\title{
Study on the Cultivation of the Innovational Ability of Practice Teaching in Colleges
}

\author{
Hongxin Li \& Mengchun Ding \\ School of Economics and Management \\ Changchun University of Science and Technology \\ Changchun 130022, China \\ E-mail: 609677303@qq.com
}

\begin{abstract}
The practice teaching which can not be replaced by others is very important to cultivate students' innovational ability. As viewed from the cultivation of innovational ability, the practice teaching still has many problems. In various forms of the practice teaching, students' innovational thinking should be cultivated mainly, and the practice teaching system which is propitious to the cultivation of innovational ability should be established.
\end{abstract}

Keywords: Colleges, Practice teaching, Innovational ability

As an important part of higher education, the practice teaching is propitious to cultivate students' innovational spirit and ability and comprehensively push the quality education. For the problem how to cultivate students' innovational ability in the practice, many colleges lack in deep considerations and systematically scientific measures.

\section{The practice is the unique approach to form the innovational ability}

The innovational ability is the ability that people innovate in old things and create new things, and it has many characters such as the comprehensive specificity and the structure optimization. The genetic constitution is the physiological base and necessary material premise to from human innovational ability and it potentially decides the type, speed, and level of the future development of individual innovational ability. The environment is the important condition to enhance human innovational ability and it influences the development speed and level of individual innovational ability. The practice is the unique approach to form human innovational ability, and based on certain knowledge accumulation, the innovational ability can be trained and elicited. The practice is also the standard to test the level of innovational ability and the result of innovational activity.

2. Analysis of the phenomena and causes that make against the cultivation of students' innovational ability in the practice teaching of colleges

2.1 The phenomena that make against the cultivation of students' innovational ability in the practice teaching of colleges

2.1.1 Most practice teaching still continues traditional teaching mode

In practice, a complete practice teaching system which can cultivate students' innovational ability is deficient, or there is a system or standard, but the exertion is not complete, or the form of the practice system can not be applied.

\subsubsection{Students implements practices passively}

In some practical parts, most students passively participate in the practice, and the object, method, and programs of the practice are decided by teachers, and students can only complete the task of practice along the route constituted by teachers, and their creative thinking and imaginations can not be fully exerted.

\subsubsection{The topic deviates from practice and students lack for interests}

The topics of some practices combining with the practice are too complex to suit for students. Some practices don't connect with the reality, and good practical problems are deficient. And because of limited finance, some practices lack in corresponding practical locations, tools, and measures, and they are simulated, and difficult to combine with the reality, so students lack in interests and only simply deal with them.

\subsubsection{Teachers lack in management to students}

In some parts of the practice, only a few general directions are decided by teachers, and students have not seriously deal with them, and only find materials from internet. Though the practice reports scraped together by students appear good, but students' innovational ability has not been cultivated well, and time and energies are wasted in fact. 


\subsubsection{Problems in various practice parts}

Taking the social survey as the example, many students copy a report to teachers. In the production practice, the proper enterprises are difficult to be found, so this part of practice becomes formally. In the graduate practice, most colleges let students to find their practice enterprises, and in practice, some students are busy in looking for jobs, and some students have not enough ability to participate in practice, and some students want for graduate education, so the graduate practice often becomes a mere formality.

\subsection{Causes that make against the cultivation of students' innovational ability in the practice teaching of colleges}

2.2.1 Teachers can not really understand the idea of innovational education, and have not established new modern education concepts

The modern education concept should mainly cultivate students' learning ability, application ability and innovation ability.

2.2.2 The practice teaching has not been an independent training system to cultivate students' comprehensive innovational ability

The teaching system of the practice teaching should include the system of teaching content, the system of teaching management, the system of teaching supervision, and the system of teaching evaluation, but there is still not a set of effective performance assessment index to evaluate the cultivation of the innovational ability.

\subsubsection{The practice teaching has not been put on the same important position with the theoretical teaching}

Though the practice teaching is emphasized orally, but in practice, it is often becomes a mere formality. One prominent problem is the sufficient capital investment. To obtain good effect of practice teaching, students should be divided into many groups, and several teachers should instruct them and seriously correct the practice reports, that needs teachers pay more labors, but at present, most colleges only offer fewer hours than the theoretical courses. In addition, the practice teaching often needs the locations outside the university, and it needs traffic, residents, and even practice fees, but the outlay of the practice teaching often has too many problems to deal with, that seriously blocks teachers' enthusiasm to instruct the practice.

2.2.4 College students advocate consciousness of practice more and participate in behaviors of practice less

On the one hand, students want to enhance their innovational ability, and they have innovational consciousness and active spirit status, but the limitation of the conditions about the creative practice in university and the situation that students often have not fully utilize the conditions of school restrain the future development of students' innovational ability. On the other hand, students' enthusiasms often can not be implemented, and their active functions have not been exerted enough. For example, though the innovational passion can generate the inspiration of innovation, but the target of innovation is not specific, and the durative drive is deficient, so the inspiration will disappear soon.

\subsubsection{Many students copy reports seriously}

Nowadays, convenient searching method of materials and quick communication mode make students to obtain materials quickly, and they often modified little and hand in the practice report, and even some students copy the practice reports from other universities and senior students' reports, and teachers usually can not find these situations.

\section{Advices to cultivate students' cultivation ability in practice teaching for colleges}

\subsection{Cultivate innovational thinking in practice}

\subsubsection{Design good questions and mainly cultivate students' consciousness of question}

Question is the start of thinking, and the start of innovation. In the practice teaching, the smart establishment of question situation is the key part. In the loose atmosphere intentionally created, students can ask questions freely. Teachers should publicly appraise students' curiosity and exploratory behaviors, and allow them look for answers according to their routes and approaches, and teachers should never restrain them by rules and regulations, and often encourage them to show their own individual opinions. At the same time, question is the approach of thinking, and the essential to settle question is the process to continually propose problems. When designing questions in practice teaching, the situation, adaptability, validity, topic, interest, and volatilization of questions should be emphasized.

\subsubsection{Cultivation of innovational thinking}

Innovational thinking develops based on general thinking, and it is the result of postnatal training and cultivation. According to general rule of the cultivation of innovational thinking, following aspects should be emphasized in practice teaching, i.e. spreading the wings of "imagining" and looking for practice topics and questions, looking for multiple answers and cultivating the divergent thinking and developing the intuition thinking. Young people often feel sensitively, and have active imagination, and many new ideas and opinions will appear suddenly, and they should capture innovational thinking timely. 


\subsection{Cultivate students' innovational ability in various practice teaching forms}

Various parts of the practice should be developed according to the characters of various specialties and the requirements of the society for talents.

\subsubsection{Organize students to implement social investigation and research}

In the practice teaching, the persons who have innovational ability should be mainly cultivated, and the group discussion should be the necessary part of the organization form. By the instruction of teachers, students should go to counties, enterprises, and streets to survey for special topics. Concretely, 3 to 5 students can compose one group, and members in the group can cooperate and divide works, and analyze and research the materials based on relative theories and deep survey, and find out rules. The survey reports require systematic analysis of the materials, and practice researches combining knowledge, and after the survey, several classroom discussions can be carried out. In the classroom discussion that students voluntarily enter for, after teacher checks up the topics of the handed reports and the quality of the contents, students can show their own research results and opinions. After other students listen to the reports, they can ask questions according to the contents and the student on the platform should answer them. The classroom discussion may be favored by students, and they will actively participate in the discussion and show their own opinions.

\subsubsection{Part of course practice}

The part of course practice teaching is a teaching part to cultivate students' practice ability and innovation ability in various specialties, and by the course practice, students can grasp the theoretical knowledge and validate the theory, so their learning interests can be inspired, and their strict science style can be cultivated, which require teachers design good practice content and topic combining the teaching contents, and the colleges should establish good teaching center of course practice and good teaching software. The economic management experiment center of Shanghai University of Science and Technology is the good example, and it can enhance students' innovational practice ability, optimize the experiment teaching system, and emphasize the establishment of experiment teaching.

\subsubsection{Part of skill training}

College students' practice skill is the basic ability to survive successfully in the society, and it includes the ability of work and the technology of work. By the skill training, students can learn basic using method of tools, and grasp some basic operation criterion and skills, and exercise the innovational ability. At present, many colleges have adopted certain measures to make graduates grasp certain skills and acquire corresponding technical certificates, and establish good base for students' employments.

\subsubsection{Research of the comprehensive innovational practice teaching development}

The development research of the comprehensive innovational practice teaching is a systematic project, and it should be implemented according to the characters of the specialty and the practice of the college. For example, based on the existing practice teaching equipments, the specialty of the engineering can integrate original practice equipments, and introduce the computer technology and new intelligent technology to optimize the comprehensive innovational practice teaching system. In addition, according to the basic process of the development and design of electric and mechanic products, the mechanical and electrical major can design the teaching environment of engineering application, and students can complete the series mechanic engineering experiment and the comprehensive innovational experiment content in this teaching environment, and adopt the computer simulation to design and realize the project of innovational design, which can cultivate students' innovational ability well.

\subsection{Establish the practice teaching system and cultivate the innovation ability}

\subsubsection{Reform the contents of practice teaching and strengthen the cultivation of innovational ability}

At present, many stable bases of practice teaching are unworthy of their name, and many specialties can not be implemented. Students should be encouraged to establish their own simple businesses, for example, the students graduated from the marketing specialty can engage in sale promotion or sell vegetables, and the students graduated from the mechanism specialty can fix machines even engage in obligation services. By this way, students can easily find the practice enterprises which would want to accept students, and the effect of the practice will certainly good. By the measures such as "the cultivation of practice teaching innovation ability" and "the game of business plan", students' scientific and technical consciousness and innovational ability can be strengthened. Junior students can develop the innovational activities of science and technology based on relative laboratory, and senior students can participate in the research activities of science and technology group as soon as possible to cultivate their initial innovational consciousness and ability in various comprehensive design experiments.

3.3.2 Establish the effective standards that make for the supervision and evaluation of practice teaching to cultivate students' innovational ability 
The existing teaching supervision and evaluation system of the practice teaching lacks in microcosmic and concrete evaluation standards, much more the evaluation standards from the angle of innovational ability. Therefore, the microcosmic effective standards of main practice forms in colleges should be established as soon as quickly, not only some macro standards such as the practice time, the amount of production-learning-research base, the complete practice documents, and practice reports.

\section{References}

Changsha Evening News. (2003). Case Teaching and the Cultivation of Innovational Ability. [Online] Available: http://www.sina.com.cn. (Nov, 2003).

He, Zhen. (2009). Consideration of Innovational Problems about Talent Cultivation. [Online] Available: http://www.gdou.edu.cn/xcb/source/column.asp /. (Feb, 2009).

Liang, Yue. (2008). Cultivation of Students' Innovation Consciousness under New Course Standards. Teaching Communication. No.10.

Li, Peigen. (2006). Active Practice: the Key to Cultivate Innovational Ability. [Online] Available: http://www.china.com.cn/. (July, 2006).

Zhu, Qingshi. (2008). How to Cultivate Innovational Ability. [Online] Available: http://www.ustc.edu.cn/zh_CN/column/000010/. (July, 2007). 